\title{
6
}

\section{Robustness of the Rainpak Algorithm for Storm Direction and Speed}

\author{
William James, Peter Nimmrichter, W. Robert C. James and Ronald \\ Scheckenberger
}

The objective of this chapter is to present an investigation of the robustness of an algorithm for storm direction and speed. The algorithm is used in a utility called "Rainpak" in PCSWMM. In this chapter we first present an approach for estimating the mean speed and direction of a multi-cellular rainstorm using rateof-rain gages. The code for spatial analysis of storms and their cells is described. Then we present a Monte Carlo analysis of rain storms observed in Toronto and Hamilton, Ontario, in which we demonstrate the robustness of the analysis with respect to observational uncertainty.

\subsection{Introduction}

Ground level rate-of-rain gages provide the primary information from which the Rainpak module provided in PCSWMMGIS computes storm cell velocity (speed and direction). Errors in ground rainfall measurement are many; they result from improper calibration of equipment, equipment malfunctions, poor location of rain gages, equipment limitations, and from data collection and reduction. Erroneous data may produce amplified errors in computed results, depending on the computational procedures in the algorithm, and may cast doubt on the accuracy of the computations. Algorithms used in Rainpak are subject to the same uncertainty. Thus the purpose of this work is to establish the robustness of the velocity algorithm in relation to various errors in rain gage observations.

James, W., P. Nimmrichter, R. James and R.B. Scheckenberger. 2002. "Robustness of the Rainpak Algorithm for Storm Direction and Speed." Journal of Water Management Modeling R208-06. doi: 10.14796/JWMM.R208-06.

(C) CHI 2002 www.chijournal.org ISSN: 2292-6062 (Formerly in Best modeling practices for Urban Water Systems. ISBN: 0-9683681-6-6) 


\subsection{The Storm and Cell Velocity Algorithm}

In the Rainpak algorithm, storm vectors are produced by a geometric analysis of optimum lags between cell occurrences throughout the observation network (Scheckenberger, 1983; Nimmrichter, 1986). As shown in Figure 6.1, optimal lags are computed by serial lag cross-correlations between two hyetographs (Marshall, 1980). Using a method that assumes that storm cell planforms are regular and conformable, storm cell velocities are computed from the simple geometric relations given below in Equations (6.1) to (6.3) (Scheckenberger, 1983). Correlograms, vectors and rosettes of means are plotted interactively (James et al., 2000).

Thunderstorms display intense, short-duration rainfall, rapidly varied spatially. High variability in both time and space is possibly explained by turbulence effects at all scales. Certain features, however, even for multicellular storms, maybe identified, such as cell plan form, and peak rain intensity, and these show some degree of persistence as the storm system tracks across an urban area. Experience shows that the drawback to tracking an identifiable feature is the subjectivity involved (Nimmrichter, 1986). Rainpak in PCSWMMGIS estimates the speed and direction of a cell by computing the likely lag time for a particular cell's overall hyetograph shape to pass between two identified rain gages. Subjectivity is avoided by computing the serial lag correlation and taking the optimal lag as the time of travel, provided that the optimal correlation is good (e.g. $>0.85$ ). Determinations with a lower correlation coefficient are ignored. Underlying the method is the assumption that cell plan forms are on the average, simple and conformable.

It can be shown that, to compute one velocity vector (direction and speed) of a cell, Cartesian co-ordinates of at least three rain gages and the relative time for the general hyetograph shape to arrive at each gage are required. Every combination of three rain gages produces a cell velocity vector. Because for a network of several gages, so many vectors are computed, a mean storm vector is determined by taking the vector mean. In fact most networks produce sufficient data that satisfactory means may be obtained by ignoring all determinations that are more than two standard deviations from the mean. In the algorithm, vector speeds and directions (DIR) are determined as follows (Scheckenberger, 1983):

Let:

$(x, y)$ be the Cartesian co-ordinates representing three rain gage locations denoted $1,2,3$, $\left(X^{T}, Y^{T}\right)$ be the transformed co-ordinates, where the $\mathrm{X}$ axis represents the storm direction, $\mathrm{Y}$ is orthogonal to $\mathrm{X}$, 


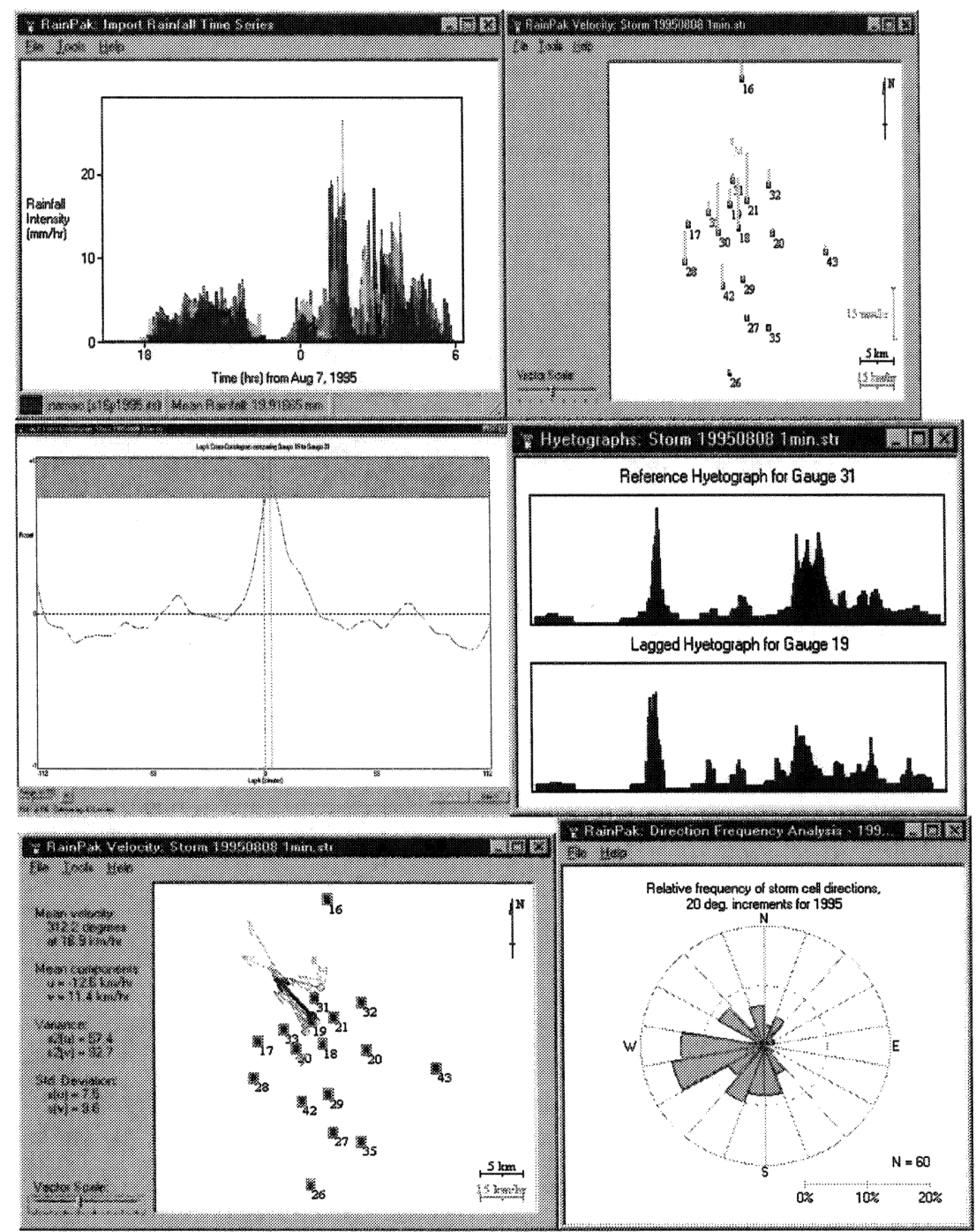

Figure 6.1 Procedures used in the Rainpak module of PCSWMM (rain data courtesy City of Edmonton).

Top L: Derived 12-h 1-min increment hyetographs for all 20 gages, Aug 71995.

Top R: Hyetograph playback at selectable speed and scale.

Middle L: Auto-correlogram showing optimal lag.

Middle R: Two selected hyetographs auto-lagged for max serial correlation.

Btm L: Computed cell velocities for selected hyetographs (heavy $=$ vector mean).

Btm R: Relative frequency of computed storm velocities for 1995 cells. 
$\alpha$ be the angle of the transformation,

$v_{s}$ be the cell speed $\Delta X^{T} / \Delta \mathrm{t}$, and

$\Delta t_{(2-1)}$ be the time of travel between gages 1 and 2 .

Then:

$$
\begin{aligned}
v_{s} & =\left(x_{1} \cos \alpha+y_{1} \sin \alpha-x_{2} \cos \alpha-y_{2} \sin \alpha\right) / \Delta t_{(2-1)} \\
& =\left(x_{2} \cos \alpha+y_{2} \sin \alpha-x_{3} \cos \alpha-y_{3} \sin \alpha\right) / \Delta t_{(3-2)}
\end{aligned}
$$

The mean velocity is taken.

Now set $A=\Delta t_{(2-1)} / \Delta t_{(3-2)}$ so that, after some manipulation,

$$
\alpha=\tan ^{-1}-\left\{x_{1}-(A+1) x_{2}+A x_{3}\right\} /\left\{\left(y_{1}-(A+1) y_{2}+A y_{3}\right\}\right.
$$

Comprehensive tests on this methodology were carried out and reported by Nimmrichter (1986) and James and James (1996).

Objective evaluation of the effect of input errors on the velocity analysis code is difficult. A number of different approaches are available, each with individual strengths and weaknesses: (i) Monte Carlo simulations, (ii) statistical derivations, and (iii) first-order analysis. In simple applications the three methods have produced similar results (Nimmrichter, 1986). The advantage of the Monte Carlo method is that it is easy to understand and simple to apply to problems in which some variation of the input variables is expected. In this method a series of random, independent events is generated (Sobol, 1974). The average of the results of all trials provides a better understanding of the estimate of the objective function. The drawback of this method is the extensive computing resources required in comparison with the other two methods.

In his earlier study, the hyetograph analysis used by Nimmrichter (1986) was based on estimated time-of-peak rain-rate, the same method used by Scheckenberger (1983). However the present study uses direct determination of times-of-travel $\Delta t_{(2-1)}, \Delta t_{(2-3)}$ and $\Delta t_{(3-1)}$ between the rain gages. Note however that the same velocity algorithm was used by Nimmrichter, and the robustness of that algorithm is the focus of this chapter.

\subsection{Sensitivity of Storm Velocity to Timing Error}

Nimmrichter wrote program STSEN to generate a series of perturbations, following either a uniform or normal distribution, and some of the results of his series of 136 runs are described in the following sections. Observed hyetographs 
for Toronto and Hamilton were used, as shown in Table 6.1. Each run usually consisted of 1000 trials. A trial consists of (i) the generation of a random "timing error" sequence, (ii) modification of the observed rainfall time-of-travel using the "timing error" sequence and (iii) running the velocity algorithm, using the fictitious time-of-travel dataset. This amounted to a total of 136,000 runs of the velocity algorithm.

Table 6.1 Storm cells and tests for Monte Carlo timing error analysis.

\begin{tabular}{cccc}
\multicolumn{5}{c}{ City of Toronto } \\
\hline Test & $\Delta \mathrm{t}(\mathrm{min})$ & Storm & \# Trials \\
\hline 1 & 5 & 19790610 Cell 1 & 1000 \\
2 & 5 & 19770706 Cell 1 & 1000 \\
3 & 5 & 19750823 Cell 3 & 1000 \\
4 & 5 & 19800619 Cell 2 & 1000 \\
5 & 5 & 19790630 Cell 2 & 1000 \\
\multicolumn{5}{c}{} \\
\hline \multicolumn{5}{c}{ Hamilton-Wentworth Region } \\
\hline Test & $\Delta \mathrm{t}$ (min) & Storm & \# Trials \\
\hline 1 & 1 & 19810811 Cell 1 & 1000 \\
2 & 1 & 19820728 Cell 2 & 1000 \\
3 & 1 & 19820929 Cell 1 & 1000 \\
4 & 1 & 19830729 Cell 3 & 1000 \\
5 & 1 & 19830801 Cell 1 & 1000 \\
\hline
\end{tabular}

STSEN automatically altered the time-of-travel between each pair of rain gages by plus and minus $5 \mathrm{~min}$. This was repeated for every rain gage and the resultant velocity vector and its standard deviation were determined. This analysis may be useful if there is a suspected problem of synchronization of rainfall records (admittedly less likely these days where networked systems are more common).

To determine the effect of timing error on the resultant storm velocity vector, the fictitious time-of-travel was assumed to follow a normal distribution with a mean equal to the observed time-of-travel and various standard deviations were used to define different levels of confidence in the records (note that the time-of-travel for this Monte Carlo analysis was taken to occur in the middle of the time step, i.e. all observed times-of-travel were shifted by $2.5 \mathrm{~min}$ for the City of Toronto network and by $0.5 \mathrm{~min}$ for the Hamilton-Wentworth network). Levels of confidence of $80,85,90,95,96,97,98$ and $99 \%$ were tested.

The first phase of the sensitivity analysis indicated that the information content of the rainfall record is different for every storm event and that similar perturbations on the timing of different cells affect velocity estimates differently. 
In other words the orientation of the cell velocity vector with respect to the planform arrangement of the rain gages being analyzed, produces results of varying uncertainty. Thus three rain gages arranged in a line orthogonal to the cell track do not produce useful information. So the resultant distribution of
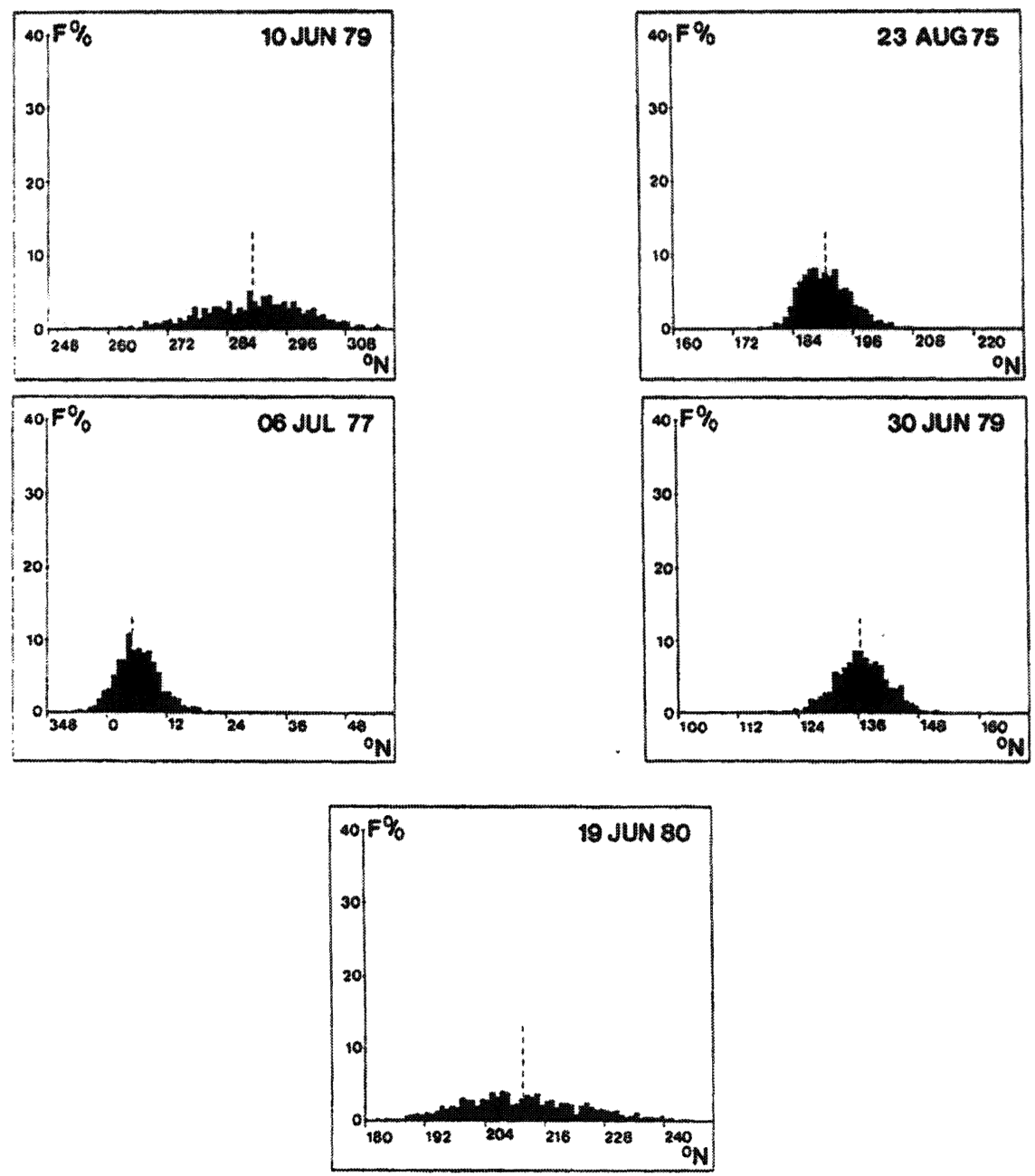

Figure 6.2 Time resolution frequency plots for storm cell direction for five Toronto storms. 
estimates is evidently different for all storms, and a generalization for different storms in the rainfall record cannot be made about the variability of average cell velocity estimates to random timing errors. Figures 6.2 and 6.3 show very different distributions of estimates of direction that were obtained for various storms.
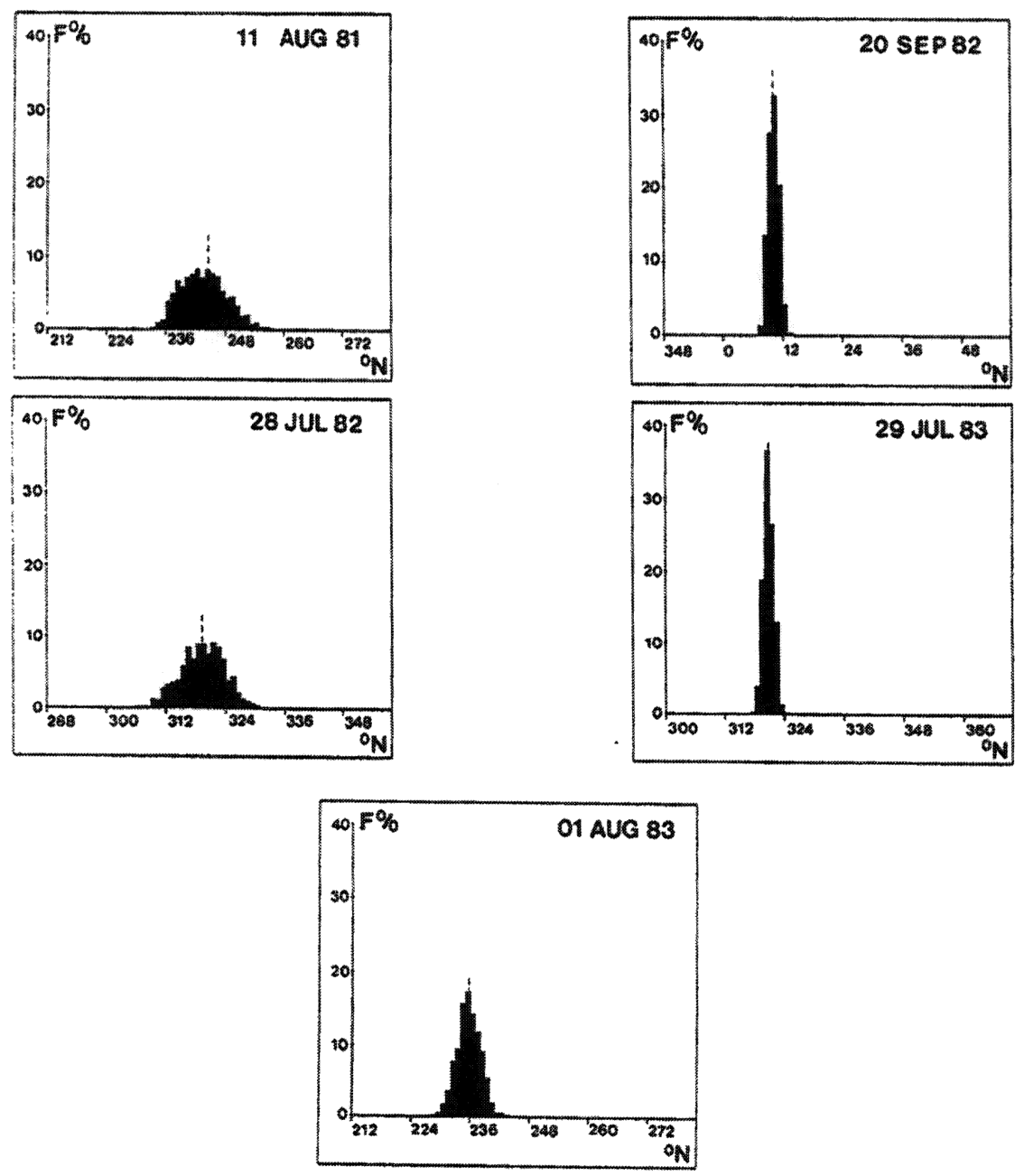

Figure 6.3 Time resolution frequency plots for storm cell direction for five Hamilton storms. 

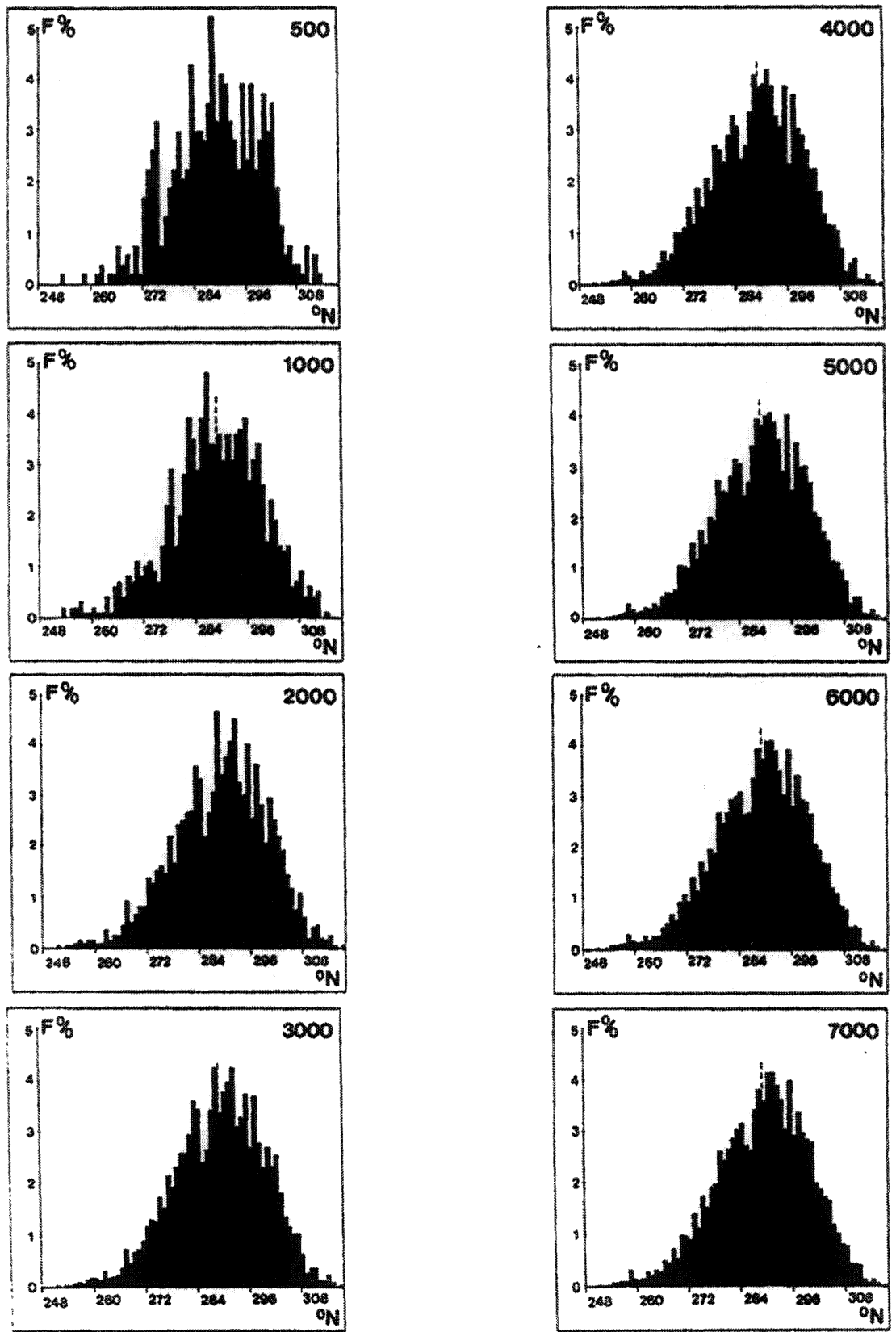

Figure 6.4a Time resolution frequency plots - effect of number of trials on storm cell direction estimates, 500 - 7000 trials. 

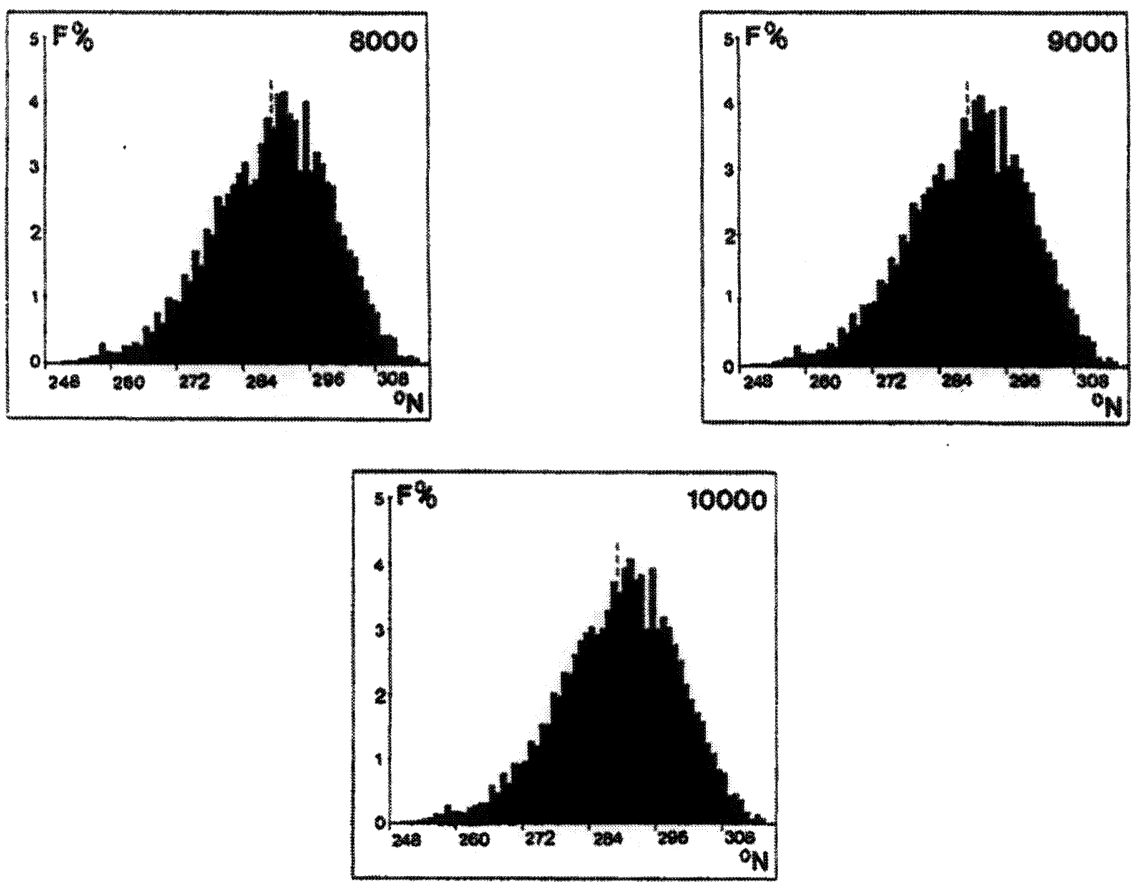

Figure 6.4b Time resolution frequency plots - effect of number of trials on storm cell direction estimates, $8000-10000$ trials.

\subsection{Sensitivity of Storm Velocity to Timing Resolution}

Apart from any errors which may occur due to the operation of the gages, the analysis of storm kinematics is restricted by the temporal resolution of the rainfall record. The velocity algorithm requires accurate times-of-travel but (as in the case of the Toronto data) a time step of 5 min gives no information as to when the peak intensity occurs within the time step. The peak intensity is just as likely to have occurred at the beginning or end of the time step.

The results of the trials are given in Table 6.2 and Figures 6.2 and 6.3. Results indicate that (i) not knowing the true time-of-travel of a storm event can cause wide variations in the possible estimates of the cell velocity and again (ii) the information content of the rainfall record for different storms is different.

Ten tests using uniformly distributed perturbations were carried out on the storm of 19790610 (Cell \#1). The results of these tests, shown in Table 6.3, indicate that the variability of the statistical parameters over many identical tests is minor. 
Table 6.2 The effect of timing resolution on Rainpak velocity estimates.

\begin{tabular}{|c|c|c|c|c|c|c|c|c|c|}
\hline Storm & Cell & $\alpha$ & Var & Std & Skew & Spd & Var & Std & Skew \\
\hline \multicolumn{10}{|c|}{ CITY OF TORONTO } \\
\hline 19790610 & 1 & 289 & 117.57 & 10.84 & -0.36 & 48.0 & 47.51 & 6.89 & 1.12 \\
\hline 19770706 & 1 & 5 & 18.94 & 4.35 & -0.38 & 24.3 & 28.35 & 5.32 & 6.42 \\
\hline 19750823 & 3 & 191 & 23.36 & 4.83 & 0.65 & 17.6 & 2.62 & 1.62 & 0.47 \\
\hline 19790630 & 2 & 137 & 26.52 & 5.15 & 0.01 & 31.5 & 17.18 & 4.14 & 1.32 \\
\hline 19800610 & 2 & 212 & 142.70 & 11.95 & 0.30 & 34.9 & 25.49 & 5.05 & 2.02 \\
\hline \multicolumn{10}{|c|}{ HAMILTON-WENTWORTH REGION } \\
\hline 19810811 & 1 & 245 & 20.86 & 4.57 & 0.39 & 52.2 & 38.77 & 6.23 & 0.96 \\
\hline 19820728 & 2 & 319 & 18.17 & 4.26 & 0.98 & 57.5 & 14.11 & 3.76 & 0.76 \\
\hline 19820920 & 1 & 10 & 1.18 & 1.09 & -0.01 & 15.1 & 0.07 & 0.26 & -2.89 \\
\hline 19830729 & 3 & 321 & 0.73 & 0.85 & 418.44 & 30.8 & 2.74 & 1.66 & 0.97 \\
\hline 19830801 & 1 & 236 & 5.59 & 2.36 & 3.54 & 51.5 & 4.68 & 2.16 & 1.02 \\
\hline
\end{tabular}

NOTE: All tests were conducted using 1000 trials.

Table 6.3 Variability of statistical parameters.

\begin{tabular}{llllllllll}
\hline $\begin{array}{c}\Delta t \\
(\mathrm{~min})\end{array}$ & Test & Dir & Var & Std & Skew & Speed & Var & Std & Skew \\
\hline 5 & 1 & 289 & 117.57 & 10.84 & -0.36 & 48.0 & 47.51 & 6.89 & 1.12 \\
5 & 2 & 289 & 112.01 & 10.60 & -0.38 & 47.9 & 39.51 & 6.29 & 0.83 \\
5 & 3 & 289 & 105.26 & 10.26 & -0.14 & 47.9 & 44.42 & 6.66 & 1.37 \\
5 & 4 & 289 & 116.99 & 10.82 & -0.36 & 47.7 & 40.49 & 6.36 & 1.53 \\
5 & 5 & 289 & 110.07 & 10.49 & -0.48 & 47.9 & 43.49 & 6.59 & 1.12 \\
5 & 6 & 289 & 119.11 & 10.91 & -0.45 & 48.1 & 52.64 & 7.26 & 1.44 \\
5 & 7 & 289 & 112.99 & 10.63 & -0.49 & 47.9 & 42.01 & 6.48 & 1.26 \\
5 & 8 & 289 & 129.10 & 11.36 & -0.49 & 48.2 & 45.69 & 6.76 & 1.47 \\
5 & 9 & 289 & 119.22 & 10.92 & -0.45 & 48.4 & 51.37 & 7.17 & 1.48 \\
5 & 10 & 289 & 118.32 & 10.88 & -0.39 & 48.2 & 42.46 & 6.52 & 0.92 \\
\hline
\end{tabular}

The following units are applicable to the above Table.

${ }^{\circ} \mathrm{N}$ for direction (Dir) $\mathrm{km} / \mathrm{h}$ for speed (Spd)

${ }^{0} \mathrm{~N}^{2}$ for variance (Var) $(\mathrm{km} / \mathrm{h})^{2}$ for variance

${ }^{\circ} \mathrm{N}$ for standard deviation (Std) $\quad \mathrm{km} / \mathrm{h}$ for standard deviation

Tests were also conducted to determine the effect of the number of trials on the statistical parameters. The results of these tests are given in Table 6.4 and illustrated in Figures 6.4a, 6.4b and 6.5. Even at low numbers of trials (i.e. $10)$, evidently a reasonable estimate of the cell velocity can be achieved.

One difficulty with the $5 \mathrm{~min}$ timing resolution on rainfall records is that, in many cases, times-of-travel at more than three gages is identical, making calculation of the cell speed impossible (unless of course the cell was truly stationary). Nimmrichter then modified the rainfall timing slightly so that no 

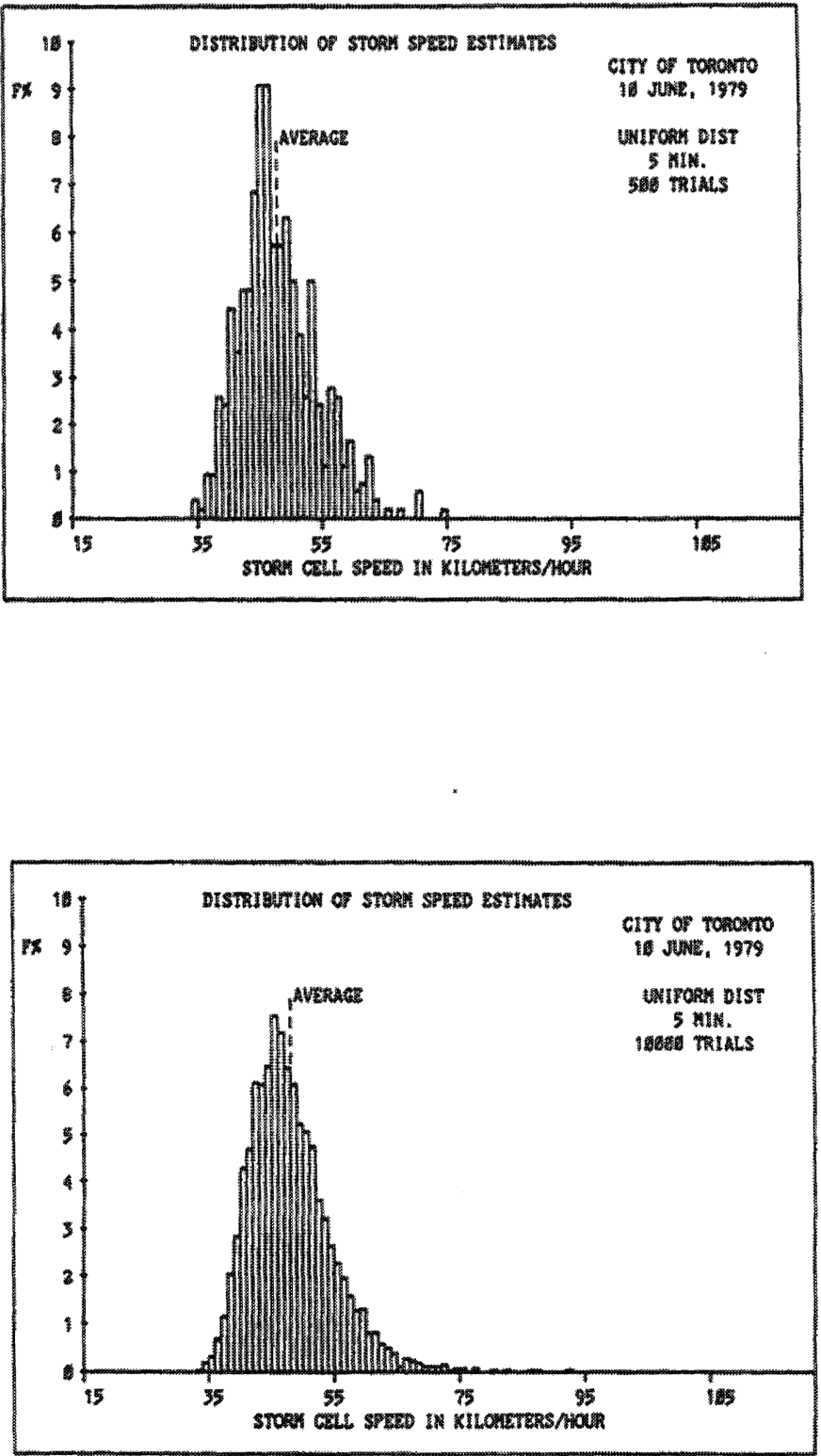

Figure 6.4 Time resolution frequency plots - effect of number of trials on storm cell speed estimates -500 and 10000 trials. 
2. The confidence in a velocity estimate may be increased by including more rain gages in the simulation.

3. The geometric arrangement of rain gages within a collection network with respect to expected storm tracks may be a factor when analyzing data for storm dynamics.

4. The information content, for storm dynamics, of the rainfall record varies from one storm event to another.

5. Monte Carlo simulation can be used to avoid the influence of operator bias when difficulties of three or more gages have identical times-of-travel.

6. Over many Monte Carlo trials, random timing errors in a rain-fall record may not cause deviations from the "true" direction. Also, the true mean direction can be generated from a reasonably small number of trials. However, any given trial may depart significantly from the mean (by 50 or $60^{\circ}$ or more in some cases, where the local hyetograph is poor, perhaps just one or two rain gage bucket tips).

\section{References}

Fiering, M.B., and Jackson, B.B. 1971. Synthetic Streamflows, American Geophysical Union, Water Resources Monograph 1, Washington, 98

James, W. and Scheckenberger, R. 1983. Storm Dynamics for Urban Runoff, Proceedings of the International Symposium on Urban Hydrology, Hydraulics and Sediment Control, University of Kentucky, Lexington, Kentucky, July 25-28, pp. 11-18.

James, W.R.C. and James, W. 1996. Analysis of rain storm dynamics in the City of Edmonton. Interim report, CHI R197. 5 pp.

James, W., James, W.R.C., and Chan, A.M.C. 2000. Analysis of spatially-kinematic using a web group decision support system, and generation of long-term, finetime-resolution rain, for urban water systems models. 5th Int. Workshop on Precip. in Urban Areas. "From precipitation measurements to design and forecasting modeling". Dec. Pontresina, Switzerland. Pp32-38.

Marshall, R.J. 1980. The Estimation and Distribution of Storm Movement and Storm Structure, Using a Correlation Analysis Technique and Rain gage Data, Journal of Hydrology, 48:19-39.

Nimmrichter, P. 1986. Dynamics of storms on the western shore of Lake Ontario. MEng. Thesis, McMaster U., 162pp.

Sargent, D.M. 1981. An Investigation Into the Effects of Storm Movement on the Design of Urban Drainage Systems, Public Health Engineering, Volume 9, pp. 201207. 
Scheckenberger, R. 1983. Dynamically Spatially Variable Rain Models for Storm water Management, M. Eng. thesis, McMaster University, Hamilton, Ontario.

Shearman, R.J. 1977. The Speed and Direction of Movement of Storm Rainfall Patterns, A Pilot Investigation with reference to Urban Storm Sewer Design, Meteorological Office, Brachnell, Berkshire, England, 53 PP.

Sobol, I.M. 1974. The Monte Carlo Method, translated and adapted from the second Russian edition by Robert Messer, John Stone and Peter Fortini, University of Chicago Press, Chicago, 63 pp.

Surkan, A.J. 1974. Simulation of Storm Velocity Effects of Flow from Distributed Channel Networks, Water Resources Research, Volume 10, Number 6, December, pp. 1149-1160.

Yen, B.C., and Chow V.T. 1969. A Laboratory Study of Surface Runoff Due to Moving Storms, Water Resources Research, Volume 5, Number 5, October, pp. 989-1006.

Related earlier publications by the authors

James, W. and Scheckenberger, R. 1985. RAINPAC - A Program Package for Analysis of Rainfall Inputs in Computing Storm Dynamics, Proc. of the Storm water and Water Quality Modelling Meeting, USEPA, Detroit, Michigan, EPA-600/9-85003, pp. 81-100, Jan

Nimmrichter, P. and James, W. 1985 Dynamics of Storms on the Western Shore of Lake Ontario, Proc. of the Storm water and Water Quality Modelling Conf., sponsored by USEPA and Ontario Ministry of Environment, Toronto, Ontario, published by CHI Hamilton, pp. 29-60, Dec 5-6,

Nimmrichter, P. and James, W. 1986. Storm Dynamics in the Lake Ontario Region, Water Forum '86, A.S.C.E., Long Beach, California, pp. 1452-1459, Aug 4-6, 